\title{
Application of Heterogeneous Composite Model with Consideration of Stress Sensitive in Low Permeability Gas Reservoir
}

\author{
Muwang Wu, Hao Liang \\ CNOOC China Ltd Hainan, Haikou, Hainan \\ Email: lianghao8@cnooc.com.cn
}

How to cite this paper: Wu, M.W. and Liang, H. (2020) Application of Heterogeneous Composite Model with Consideration of Stress Sensitive in Low Permeability Gas Reservoir. International Journal of Geosciences, 11, 756-767.

https://doi.org/10.4236/ijg.2020.1111038

Received: October 17, 2020

Accepted: November 23, 2020

Published: November 26, 2020

Copyright $\odot 2020$ by author(s) and Scientific Research Publishing Inc. This work is licensed under the Creative Commons Attribution International License (CC BY 4.0).

http://creativecommons.org/licenses/by/4.0/

\begin{abstract}
Stress sensitivity is a key factor affecting the productivity of single wells in low permeability gas reservoirs. A well test model for heterogeneous composite gas reservoirs under the influence of stress-sensitive effects was established. Based on the theoretical model, the well test was designed by gradually increasing the pressure difference. The relationship between abnormal high pressure and reservoir stress sensitivity was analyzed. Theoretical research shows that stress sensitivity will cause permeability damage during the production process, and the pressure drop test curve shows that the physical properties of the reservoir have gradually deteriorated. The pressure recovery test curve shows that the physical properties of the reservoir are getting better. Field practice shows that stress sensitivity is related to the formation of abnormally high pressure in the formation without considering the micro-cracks in the formation. Stress-sensitive reservoirs are generally unbalanced and compacted due to overpressure, for fluid expansion/conduction overpressure in Ledong Area. For these reservoirs, there is almost no stress sensitivity. The research results have significance for guiding the design and data interpretation of stress-sensitive reservoir.
\end{abstract}

\section{Keywords}

Ledong Area, Stress Sensitivity, Composite Gas Reservoir, Well Test Model, Undercompaction, Fluid Expansion/Conduction

\section{Research Background}

In view of the development of an ultra-high pressure gas reservoir, the stress sensitivity of the reservoir is the most discussed in China [1] [2] [3] [4] [5]. Re- 
servoir stress sensitivity refers to the decrease of reservoir pore pressure and the increase of overlying effective stress in the process of oil and gas exploitation, which leads to the decrease of reservoir permeability and porosity, and the acceleration of gas well productivity and flow pressure decline. Due to overpressure in the initial stage of the ultra-high pressure gas reservoir, the net effective overburden pressure of the rock skeleton is much higher than that of a conventional gas reservoir in the depletion production process, so it is generally considered that the stress sensitivity is stronger [6] [7]. Ledong area in Yinggehai basin has a formation pressure coefficient of more than 2.28 , which belongs to ultra-high pressure and low permeability gas reservoir. Due to the high drilling cost and difficulty in coring, it is difficult to evaluate the reservoir stress sensitivity by experiment. Considering the reservoir stress sensitivity has a significant impact on the development, a reasonable test scheme is designed for the exploration wells in the exploration stage, and the well test data are tried to be used for interpretation and acquisition Stress sensitive parameters. At present, there is no report on well test model of heterogeneous composite gas reservoir considering stress sensitivity [8] [9] [10] [11] [12]. Based on the unsteady flow theory of gas well, the well test model of heterogeneous composite gas reservoir considering stress-sensitive effect is established by using Laplace transforms and perturbation transformation principle. And then the pressure drop test and pressure build-up well test charts are drawn by using a numerical inversion algorithm and the effects of stress sensitivity, the radius of inner and outer zone and mobility ratio of the inner and outer zone on pressure performance are analyzed. The model is used to interpret the well test data of exploration wells, and the influence of different overpressure causes on reservoir stress sensitivity is discussed [13] [14].

\section{Mathematical Model of Seepage}

According to the pressure dynamic characteristics of a well in the center of a circular composite gas reservoir, the corresponding physical model is established, as shown in Figure 1. The assumptions of the model are as follows: 1)

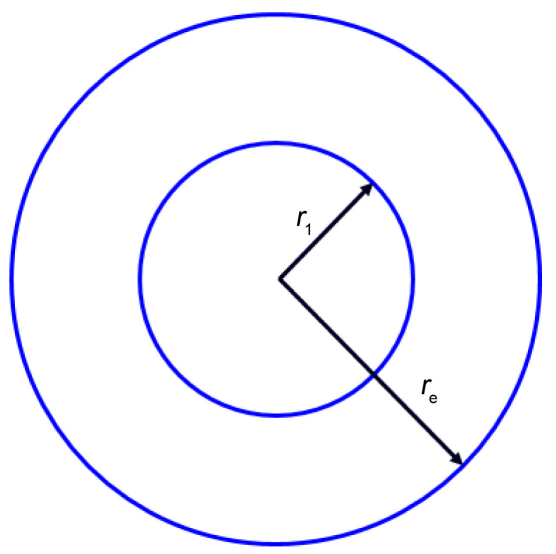

Figure 1. Schematic diagram of composite gas reservoir. 
There is a well in the center of the composite gas reservoir with fixed production, the radius of the inner boundary is $\mathrm{R} 1$, and the outer boundary is infinite; 2) The reservoir is of equal thickness, with good interlayer at the upper and lower parts; under the original conditions, the formation pressure is evenly distributed, and the internal and external regions have different physical properties; 3) The reservoir rock is slightly compressible, and the formation permeability changes with the change of effective stress; 4) The flow of fluid in the formation is isothermal; 5) The wellbore storage effect and skin factor are considered; 6) The gravity and capillary force are ignored.

Considering the influence of stress sensitivity, the seepage differential equation of composite gas reservoir can be obtained from the motion equation, the continuity equation and the state equation of natural gas [15] [16].

Seepage equation in inner region:

$$
\frac{1}{r} \frac{\partial}{\partial r}\left[r \frac{p_{1} M}{Z R T} \frac{k_{01} \mathrm{e}^{-\gamma\left(p_{\mathrm{i}}-p_{1}\right)}}{\mu_{1}}\left(\frac{\partial p_{1}}{\partial r}\right)\right]=\phi_{1} \frac{\partial}{\partial t}\left(\frac{p_{1} M}{Z R T}\right)
$$

where $r$ is the radial coordinate, $\mathrm{m}, Z$ is deviation factor of gas, $R$ is perfect gas constant, $T$ is temperature of gas, $\mathrm{K}, k_{01}$ is permeability of inner region, $\mu \mathrm{m}^{2}, M$ is molar mass of gas, $\mathrm{g} / \mathrm{mol}, p_{1}$ is the instantaneous formation pressure of inner region, $\mathrm{MPa}, p_{\mathrm{i}}$ is primary formation pressure, $\mathrm{MPa}, \gamma$ is the stress sensitivity index, $\mathrm{MPa}^{2} /(\mathrm{mPa} \cdot \mathrm{s}), \mu_{1}$ is gas viscosity of inner region, $\mathrm{mPa} \cdot \mathrm{s}$.

Seepage equation of outer zone:

$$
\frac{1}{r} \frac{\partial}{\partial r}\left[r \frac{p_{2} M}{Z R T} \frac{k_{02} \mathrm{e}^{-\gamma\left(p_{\mathrm{i}}-p_{2}\right)}}{\mu_{2}}\left(\frac{\partial p_{2}}{\partial r}\right)\right]=\phi_{2} \frac{\partial}{\partial t}\left(\frac{p_{2} M}{Z R T}\right)
$$

where $k_{02}$ is permeability of outer region, $\mu \mathrm{m}^{2}, p_{2}$ is the instantaneous formation pressure of outer region, $\mathrm{MPa}, \mu_{2}$ is gas viscosity of outer region, $\mathrm{mPa} \cdot \mathrm{s}$.

The definition of pseudo pressure is introduced:

$$
\psi=2 \int_{p_{0}}^{p} \frac{p}{\mu Z} \mathrm{~d} p
$$

where $p$ is formation pressure, $\mathrm{MPa}, p_{0}$ is initial pressure, $\mathrm{MPa}, \mu$ is gas viscosity, $\mathrm{mPa} \cdot \mathrm{s}$.

By introducing Equation (3) into Equation (1) and Equation (2), the comprehensive seepage differential equation of composite gas reservoir considering stress sensitivity can be obtained.

Differential equation of seepage in inner region:

$$
\frac{1}{r} \frac{\partial \psi_{1}}{\partial r}+\frac{\partial^{2} \psi_{1}}{\partial r^{2}}+\gamma^{*}\left(\frac{\partial \psi_{1}}{\partial r}\right)^{2}=\frac{\phi_{1} \mu_{1} C_{2}(p)}{k_{01}} \mathrm{e}^{\gamma^{*}\left(\psi_{\mathrm{i}}-\psi_{1}\right)} \frac{\partial \psi_{1}}{\partial t}
$$

where $\psi_{1}$ is pseudo pressure of inner region, $C_{2}$ is outer region isothermal compression coefficient of gas, $\mathrm{MPa}^{-1}, \gamma^{*}$ is the stress sensitivity index of pseudo pressure.

Differential equation of seepage in outer region: 


$$
\frac{1}{r} \frac{\partial \psi_{2}}{\partial r}+\frac{\partial^{2} \psi_{2}}{\partial r^{2}}+\gamma^{*}\left(\frac{\partial \psi_{2}}{\partial r}\right)^{2}=\frac{\phi_{2} \mu_{2} C_{2}(p)}{k_{02}} \mathrm{e}^{\gamma^{*}\left(\psi_{\mathrm{i}}-\psi_{2}\right)} \frac{\partial \psi_{2}}{\partial t}
$$

where $\psi_{2}$ is pseudo pressure of outer region.

The initial condition is:

$$
\psi_{1}(r, t=0)=\psi_{2}(r, t=0)=\psi_{\mathrm{i}}
$$

The inner boundary condition is:

$$
\left[\left.r \mathrm{e}^{-\gamma^{*}\left(\psi_{1}-\psi_{1}\right)} \frac{\partial \psi_{1}}{\partial r}\right|_{r=r_{\text {we }}}=\frac{q_{\mathrm{sc}} p_{\mathrm{sc}} T}{\pi k_{01} h T_{\mathrm{sc}} Z_{\mathrm{sc}}}+C \frac{\mu}{2 \pi k_{01} h} \frac{\partial \psi_{1}}{\partial t}\right.
$$

where, $r_{\mathrm{we}}=r_{\mathrm{w}} \mathrm{e}^{-S}$ is the effective well diameter, $\psi_{1}$ is initial pseudo pressure, $q_{\mathrm{sc}}$ is pressure in standard conditions, $\mathrm{MPa}, T_{\mathrm{sc}}$ is temperature in standard conditions, $\mathrm{K}, Z_{\mathrm{sc}}$ is deviation factor in standard conditions, $h$ is thickness of reservoir, $\mathrm{m}$.

Set connection conditions between inner and outer areas:

$$
\left.\frac{k_{01} \mathrm{e}^{-\gamma^{*}\left(\psi_{\mathrm{i}}-\psi_{1}\right)}}{\mu_{1}} \frac{\partial \psi_{1}}{\partial r}\right|_{r=r_{1}}=\left.\frac{k_{02} \mathrm{e}^{-\gamma^{*}\left(\psi_{\mathrm{i}}-\psi_{2}\right)}}{\mu_{2}} \frac{\partial \psi_{2}}{\partial r}\right|_{r=r_{1}}
$$

where $r_{1}$ is radius of inner region, $\mathrm{m}$.

$$
\psi_{1}\left(r_{1}, t\right)=\psi_{2}\left(r_{1}, t\right)
$$

The outer boundary condition is:

$$
\psi_{2}(r \rightarrow \infty, t)=\psi_{\mathrm{i}}
$$

The mathematical model of well test interpretation for composite gas reservoir with deformed medium consists of Equations (4)-(10).

\section{The Solution of Mathematical Model}

The dimensionless well test model of deformable medium composite gas reservoir is obtained by dimensionless treatment:

$$
\left\{\begin{array}{l}
\frac{1}{r_{\mathrm{D}}} \frac{\partial \psi_{1 \mathrm{D}}}{\partial r_{\mathrm{D}}}+\frac{\partial^{2} \psi_{1 \mathrm{D}}}{\partial r_{\mathrm{D}}^{2}}-\gamma_{\mathrm{D}}^{*}\left(\frac{\partial \psi_{1 \mathrm{D}}}{\partial r_{\mathrm{D}}}\right)^{2}=\frac{\mathrm{e}^{\gamma_{\mathrm{D}}^{*} \psi_{1 \mathrm{D}}}}{\mathrm{e}^{2 S}} \frac{\partial \psi_{1 \mathrm{D}}}{\partial t_{\mathrm{D}}} \\
\frac{1}{r_{\mathrm{D}}} \frac{\partial \psi_{2 \mathrm{D}}}{\partial r_{\mathrm{D}}}+\frac{\partial^{2} \psi_{2 \mathrm{D}}}{\partial r_{\mathrm{D}}^{2}}-\gamma_{\mathrm{D}}^{*}\left(\frac{\partial \psi_{2 \mathrm{D}}}{\partial r_{\mathrm{D}}}\right)^{2}=\frac{\omega}{M} \frac{\mathrm{e}^{\gamma_{\mathrm{D}}^{*} \psi_{2 \mathrm{D}}}}{\mathrm{e}^{2 S}} \frac{\partial \psi_{2 \mathrm{D}}}{\partial t_{\mathrm{D}}} \\
\left.\psi_{1 \mathrm{D}}\left(r_{\mathrm{D}}, t_{\mathrm{D}}\right)\right|_{\mathrm{D}_{\mathrm{D}}=0}=\left.\psi_{2 \mathrm{D}}\left(r_{\mathrm{D}}, t_{\mathrm{D}}\right)\right|_{t_{\mathrm{D}}=0}=0 \\
\left.r_{\mathrm{D}} \mathrm{e}^{-\gamma_{\mathrm{D}}^{*} \psi_{1 \mathrm{D}}} \frac{\partial \psi_{1 \mathrm{D}}}{\partial r_{\mathrm{D}}}\right|_{r_{\mathrm{D}}=1}=-1+C_{\mathrm{D}} \frac{\partial \psi_{1 \mathrm{D}}}{\partial t_{\mathrm{D}}} \\
\left.\frac{\partial \psi_{1 \mathrm{D}}}{\partial r_{\mathrm{D}}}\right|_{r=r_{\mathrm{D}}}=\left.\frac{1}{M} \frac{\partial \psi_{2 \mathrm{D}}}{\partial r_{\mathrm{D}}}\right|_{r=r_{\mathrm{D}}} \\
\psi_{1 \mathrm{D}}\left(r_{1 \mathrm{D}}, t_{\mathrm{D}}\right)=\psi_{2 \mathrm{D}}\left(r_{1 \mathrm{D}}, t_{\mathrm{D}}\right) \\
\lim _{r_{\mathrm{D}} \rightarrow \infty} \psi_{2 \mathrm{D}}\left(r_{\mathrm{D}}, t_{\mathrm{D}}\right)=0
\end{array}\right.
$$

The definition of dimensionless variables is shown in Table 1. 
Table 1. Dimensionless variable definition.

\begin{tabular}{lclc}
\hline \multicolumn{1}{c}{ Variables } & Expression & \multicolumn{1}{c}{ Variables } & Expression \\
\hline $\begin{array}{l}\text { Dimensionless } \\
\text { internal formation } \\
\text { pressure }\end{array}$ & $\psi_{1 \mathrm{D}}=\frac{\pi k_{01} h T_{\mathrm{sc}}}{q_{\mathrm{sc}} p_{\mathrm{sc}} T}\left(\psi_{\mathrm{i}}-\psi_{1}\right)$ & $\begin{array}{l}\text { Dimensionless outer zone } \\
\text { formation pressure }\end{array}$ & $\psi_{2 \mathrm{D}}=\frac{\pi k_{01} h T_{\mathrm{sc}}}{q_{\mathrm{sc}} p_{\mathrm{sc}} T}\left(\psi_{\mathrm{i}}-\psi_{2}\right)$ \\
$\begin{array}{l}\text { Dimensionless } \\
\text { bottom pressure }\end{array}$ & $\psi_{\mathrm{wD}}=\frac{\pi k_{01} h T_{\mathrm{sc}}}{q_{\mathrm{sc}} p_{\mathrm{sc}} T}\left(\psi_{\mathrm{i}}-\psi_{\mathrm{w}}\right)$ & Dimensionless time & $t_{\mathrm{D}}=\frac{k_{01}}{\phi_{1} \mu_{1} C_{\mathrm{t} 1} r_{\mathrm{w}}^{2}} t$ \\
$\begin{array}{l}\text { Dimensionless } \\
\text { radius }\end{array}$ & $r_{\mathrm{D}}=\frac{r}{r_{\mathrm{we}}}=r_{\mathrm{w}} \mathrm{e}^{-s}, r_{1 \mathrm{D}}=\frac{r_{1}}{r_{\mathrm{we}}}$ & Mobility ratio & $M=\frac{k_{01} / \mu_{1}}{k_{02} / \mu_{2}}$ \\
$\begin{array}{l}\text { Storage capacity } \\
\text { ratio }\end{array}$ & $\omega=\frac{\phi_{1} C_{\mathrm{t} 1}}{\phi_{2} C_{\mathrm{t} 2}}$ & $\begin{array}{l}\text { Dimensionless stress } \\
\text { sensitivity coefficient }\end{array}$ & $\gamma_{\mathrm{D}}^{*}=\gamma \frac{\mu_{\mathrm{i}} Z_{\mathrm{i}}}{2 p_{\mathrm{i}}} \frac{q_{\mathrm{sc}} p_{\mathrm{sc}} T}{\pi k_{\mathrm{o}} h T_{\mathrm{sc}}}$ \\
$\begin{array}{l}\text { Dimensionless } \\
\text { wellbore survival } \\
\text { factor }\end{array}$ & $C_{\mathrm{D}}=\frac{C}{2 \pi h \phi_{0} C_{\mathrm{t}} r_{\mathrm{w}}^{2}}$ & & \\
\hline
\end{tabular}

where subscript $\mathrm{D}$ is dimensionless variable.

In order to solve the system of Equations (11), firstly, let:

$$
\begin{aligned}
& \psi_{1 \mathrm{D}}=-\frac{1}{\gamma_{\mathrm{D}}^{*}} \ln \left[1-\gamma_{\mathrm{D}}^{*} \xi_{1 \mathrm{D}}\left(r_{\mathrm{D}}, t_{\mathrm{D}}\right)\right] \\
& \psi_{2 \mathrm{D}}=-\frac{1}{\gamma_{\mathrm{D}}^{*}} \ln \left[1-\gamma_{\mathrm{D}}^{*} \xi_{2 \mathrm{D}}\left(r_{\mathrm{D}}, t_{\mathrm{D}}\right)\right]
\end{aligned}
$$

In addition, the following perturbation transformation is used:

$$
\begin{gathered}
\xi_{\mathrm{D}}=\xi_{0 \mathrm{D}}+\gamma_{\mathrm{D}}^{*} \xi_{\text {firstD }}+\left(\gamma_{\mathrm{D}}^{*}\right)^{2} \xi_{\text {secondD }}+\cdots \\
-\frac{1}{\gamma_{\mathrm{D}}^{*}} \ln \left[1-\gamma_{\mathrm{D}}^{*} \xi_{\mathrm{D}}\right]=\xi_{\mathrm{D}}+\frac{1}{2} \gamma_{\mathrm{D}} \xi_{\mathrm{D}}^{2}+\cdots \\
\frac{1}{1-\gamma_{\mathrm{D}}^{*} \xi_{\mathrm{D}}}=1+\gamma_{\mathrm{D}}^{*} \xi_{\mathrm{D}}+\left(\gamma_{\mathrm{D}}^{*} \xi_{\mathrm{D}}\right)^{2}+\cdots
\end{gathered}
$$

Considering that the dimensionless stress sensitivity coefficient is generally small, as long as the zero solution is taken into account, the perturbation solution can satisfy the solution accuracy.

$$
\left\{\begin{array}{l}
\frac{1}{r_{\mathrm{D}}} \frac{\partial \xi_{1 \mathrm{D}}}{\partial r_{\mathrm{D}}}+\frac{\partial^{2} \xi_{1 \mathrm{D}}}{\partial r_{\mathrm{D}}^{2}}=\mathrm{e}^{-2 S} \frac{\partial \xi_{1 \mathrm{D}}}{\partial t_{\mathrm{D}}} \\
\frac{1}{r_{\mathrm{D}}} \frac{\partial \xi_{2 \mathrm{D}}}{\partial r_{\mathrm{D}}}+\frac{\partial^{2} \xi_{2 \mathrm{D}}}{\partial r_{\mathrm{D}}^{2}}=\frac{\omega_{12}}{M} \mathrm{e}^{-2 S} \frac{\partial \xi_{2 \mathrm{D}}}{\partial t_{\mathrm{D}}} \\
r_{\mathrm{D}} \frac{\partial \xi_{1 \mathrm{D}}}{\partial r_{\mathrm{D}}}=-1+C_{\mathrm{D}} \frac{\partial \xi_{1 \mathrm{D}}}{\partial t_{\mathrm{D}}} \\
\left.\xi_{\mathrm{DD}}\left(r_{\mathrm{D}}, t_{\mathrm{D}}\right)\right|_{t_{\mathrm{D}}=0}=\left.\xi_{2 \mathrm{D}}\left(r_{\mathrm{D}}, t_{\mathrm{D}}\right)\right|_{t_{\mathrm{D}}=0}=0 \\
\left.\frac{\partial \xi_{1 \mathrm{D}}}{\partial r_{\mathrm{D}}}\right|_{r=r_{1 \mathrm{D}}}=\left.\frac{1}{M} \frac{\partial \xi_{2 \mathrm{D}}}{\partial r_{\mathrm{D}}}\right|_{r=r_{1 \mathrm{D}}} \\
\xi_{1 \mathrm{D}}\left(r_{1 \mathrm{D}}, t_{\mathrm{D}}\right)=\xi_{2 \mathrm{D}}\left(r_{1 \mathrm{D}}, t_{\mathrm{D}}\right) \\
\lim _{r_{\mathrm{D}} \rightarrow \infty} \xi_{2 \mathrm{D}}\left(r_{\mathrm{D}}, t_{\mathrm{D}}\right)=0
\end{array}\right.
$$


By Laplace transformation of the Equation (15), we can get:

$$
\left\{\begin{array}{l}
\frac{1}{r_{\mathrm{D}}} \frac{\partial \bar{\xi}_{1 \mathrm{D}}}{\partial r_{\mathrm{D}}}+\frac{\partial^{2} \bar{\xi}_{1 \mathrm{D}}}{\partial r_{\mathrm{D}}^{2}}=u \mathrm{e}^{-2 S} \bar{\xi}_{1 \mathrm{D}} \\
\frac{1}{r_{\mathrm{D}}} \frac{\partial \bar{\xi}_{2 \mathrm{D}}}{\partial r_{\mathrm{D}}}+\frac{\partial^{2} \bar{\xi}_{2 \mathrm{D}}}{\partial r_{\mathrm{D}}^{2}}=u \frac{\omega_{12}}{M} \mathrm{e}^{-2 s} \bar{\xi}_{2 \mathrm{D}} \\
r_{\mathrm{D}} \frac{\partial \bar{\xi}_{1 \mathrm{D}}}{\partial r_{\mathrm{D}}}=-\frac{1}{u}+u C_{\mathrm{D}} \xi_{1 \mathrm{D}} \\
\left.\frac{\partial \bar{\xi}_{1 \mathrm{D}}}{\partial r_{\mathrm{D}}}\right|_{r=r_{1 \mathrm{D}}}=\left.\frac{1}{M} \frac{\partial \bar{\xi}_{2 \mathrm{D}}}{\partial r_{\mathrm{D}}}\right|_{r=r_{1 \mathrm{D}}} \\
\bar{\xi}_{1 \mathrm{D}}\left(r_{1 \mathrm{D}}, t_{\mathrm{D}}\right)=\bar{\xi}_{2 \mathrm{D}}\left(r_{1 \mathrm{D}}, t_{\mathrm{D}}\right) \\
\lim _{r_{\mathrm{D}} \rightarrow \infty} \bar{\xi}_{2 \mathrm{D}}\left(r_{\mathrm{D}}, u\right)=0
\end{array}\right.
$$

The solution of Equation (16) is as follows:

$$
\left\{\begin{array}{l}
\frac{1}{r_{\mathrm{D}}} \frac{\partial \bar{\xi}_{1 \mathrm{D}}}{\partial r_{\mathrm{D}}}+\frac{\partial^{2} \bar{\xi}_{1 \mathrm{D}}}{\partial r_{\mathrm{D}}^{2}}=u \mathrm{e}^{-2 s} \bar{\xi}_{1 \mathrm{D}} \\
\frac{1}{r_{\mathrm{D}}} \frac{\partial \bar{\xi}_{2 \mathrm{D}}}{\partial r_{\mathrm{D}}}+\frac{\partial^{2} \bar{\xi}_{2 \mathrm{D}}}{\partial r_{\mathrm{D}}^{2}}=u \frac{\omega_{12}}{M} \mathrm{e}^{-2 s} \bar{\xi}_{2 \mathrm{D}} \\
\frac{\partial \bar{\xi}_{1 \mathrm{D}}}{\partial r_{\mathrm{D}}}=-\frac{1}{u}+u C_{\mathrm{D}} \xi_{1 \mathrm{D}} \\
\left.\frac{\partial \bar{\xi}_{1 \mathrm{D}}}{\partial r_{\mathrm{D}}}\right|_{r=r_{1 \mathrm{D}}}=\left.\frac{1}{M} \frac{\partial \bar{\xi}_{2 \mathrm{D}}}{\partial r_{\mathrm{D}}}\right|_{r=r_{1 \mathrm{D}}} \\
\bar{\xi}_{1 \mathrm{D}}\left(r_{1 \mathrm{D}}, t_{\mathrm{D}}\right)=\bar{\xi}_{2 \mathrm{D}}\left(r_{1 \mathrm{D}}, t_{\mathrm{D}}\right) \\
\lim _{r_{\mathrm{D}} \rightarrow \infty} \bar{\xi}_{2 \mathrm{D}}\left(r_{\mathrm{D}}, u\right)=0
\end{array}\right.
$$

In Equation (19), $M_{\mathrm{TP}}=\frac{\sqrt{u}}{f_{I}(\sqrt{u})} \frac{f_{\mathrm{KI} 1}(\sqrt{u})-F}{f_{\mathrm{KI} 0}(\sqrt{u})+F}$.

where, $F=\frac{f_{\mathrm{KI} 0}\left(r_{1 \mathrm{D}} \sqrt{u}\right)+f_{\mathrm{KI} 1}\left(r_{1 \mathrm{D}} \sqrt{u}\right) R_{\mathrm{TP}}}{R_{\mathrm{TP}}-1}$,

$$
\begin{aligned}
& f_{\mathrm{KI} 0}(x)=\frac{K_{0}(x)}{I_{0}(x)}, \\
& f_{\mathrm{KI} 1}(x)=\frac{K_{1}(x)}{I_{1}(x)},
\end{aligned}
$$

where $K_{0}(x)$ is the modified Bessel function second kind (zero order), $K_{1}(x)$ is the modified Bessel function of second kind (first order), $I_{0}(x)$ is the modified Bessel function of first kind (zero order), and $I_{1}(x)$ is the modified Bessel function of first kind (first order).

$$
R_{\mathrm{TP}}=-\frac{f_{I}\left(r_{1 \mathrm{D}} \sqrt{N u}\right)}{f_{I}\left(r_{1 \mathrm{D}} \sqrt{u}\right)} \frac{f_{\mathrm{K} I 0}\left(r_{1 \mathrm{D}} \sqrt{N u}\right)}{f_{\mathrm{KI} 1}\left(r_{1 \mathrm{D}} \sqrt{N u}\right)} \frac{M}{\sqrt{N}},
$$




$$
\begin{gathered}
f_{I}(x)=\frac{I_{0}(x)}{I_{1}(x)}, \\
N=\frac{\omega_{12}}{M} .
\end{gathered}
$$

In order to obtain the solution of composite gas reservoir considering stress sensitivity, Solution (17) is sorted out as follows:

$$
\psi_{1 \mathrm{D}}=-\frac{1}{\gamma_{\mathrm{D}}^{*}} \ln \left[1-\gamma_{\mathrm{D}}^{*} \xi_{\mathrm{wD}}\left(r_{\mathrm{D}}, t_{\mathrm{D}}\right)\right]
$$

\section{Characteristics of Pressure Drop Test Curve}

The typical layout of pressure drop test for heterogeneous composite gas reservoir considering stress sensitivity is shown in Figure 2 and Figure 3. It can be seen from Figure 3 that after considering the stress sensitivity, the stress sensitivity coefficient $\gamma_{\mathrm{D}}$ will cause the curve of pressure and pressure derivative to be upwarped in the middle and later stages. The pressure derivative curve in the radial flow stage in the inner region deviates from the 0.5 horizontal line under Darcy seepage condition and the pressure derivative curve in the radial flow stage in the outer region also warps. It can be seen from Figure 4 that the larger the stress sensitivity coefficient $\gamma_{\mathrm{D}}$, the more obvious the curve of pressure and pressure derivative will be warped, which shows the characteristics of gradual deterioration of peripheral physical properties.

As shown in Figure 4 and Figure 5, the influence of parameters such as inner radius and mobility ratio on pressure drop well test curve is consistent with that of conventional composite gas reservoir. It can be seen from Figure 5 that the larger the radius of the inner region, the longer the duration of the inner region radial flow stage, and the later the outer region radial flow stage starts. It can be seen from Figure 5 that the mobility ratio mainly affects the curve characteristics of the transition section and the radial flow stage in the outer zone. The

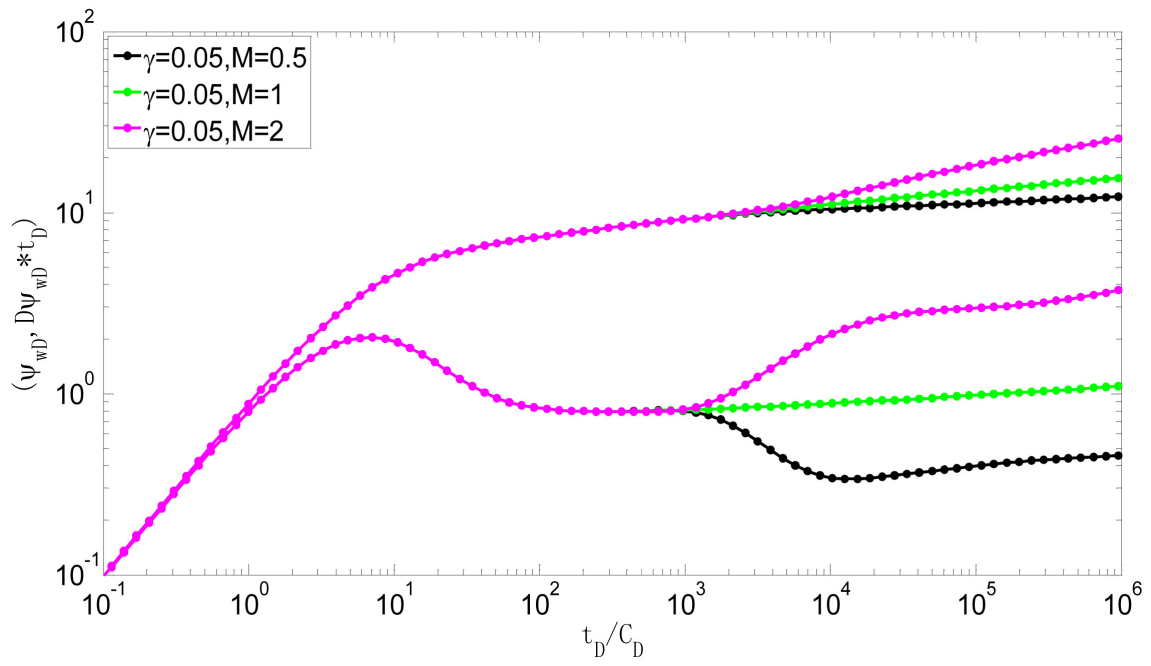

Figure 2. Typical chart of pressure drop test. 


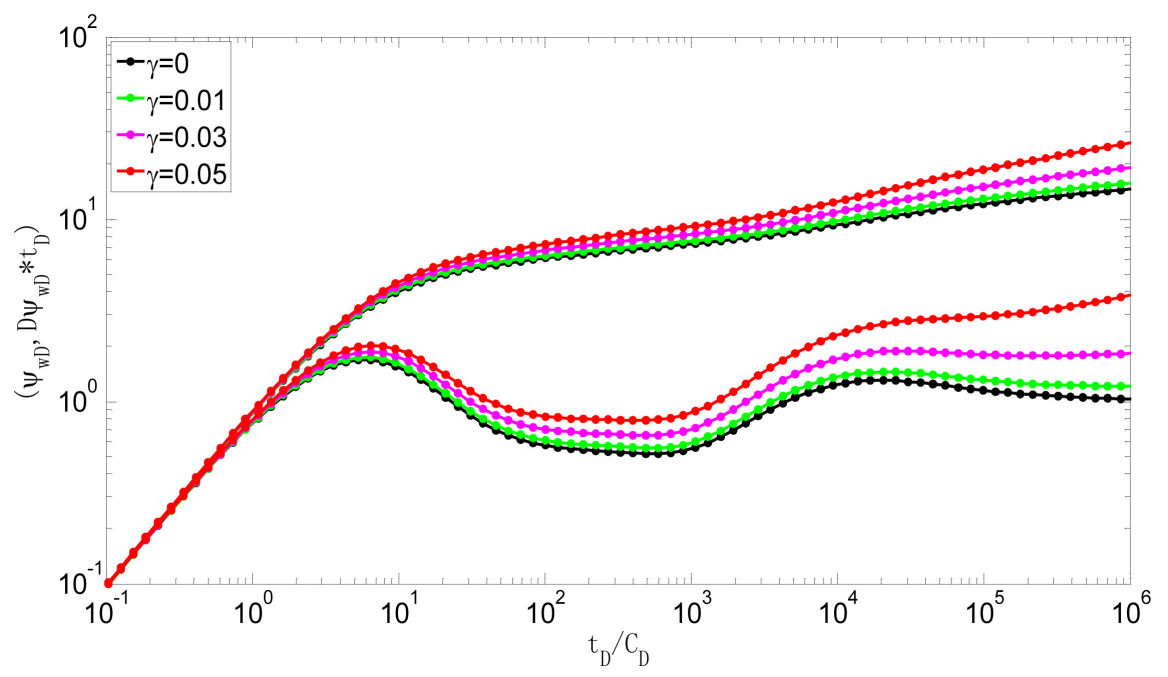

Figure 3. Pressure drop well test chart under different stress sensitivity coefficients.

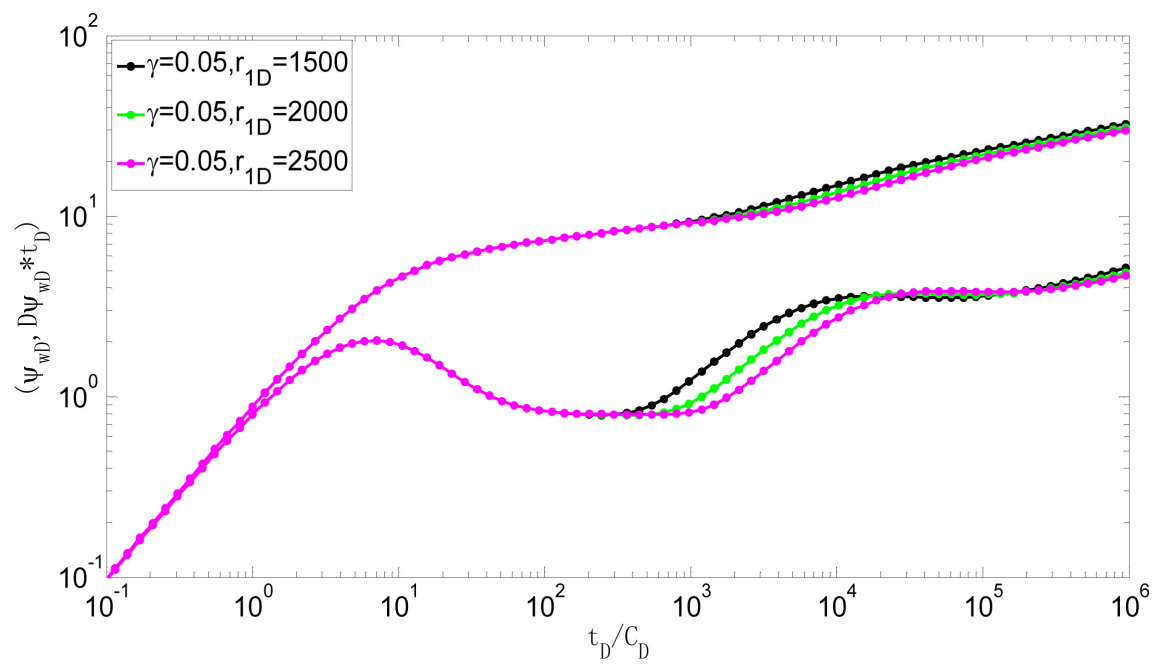

Figure 4. Pressure drop well test curves with different inner radius.

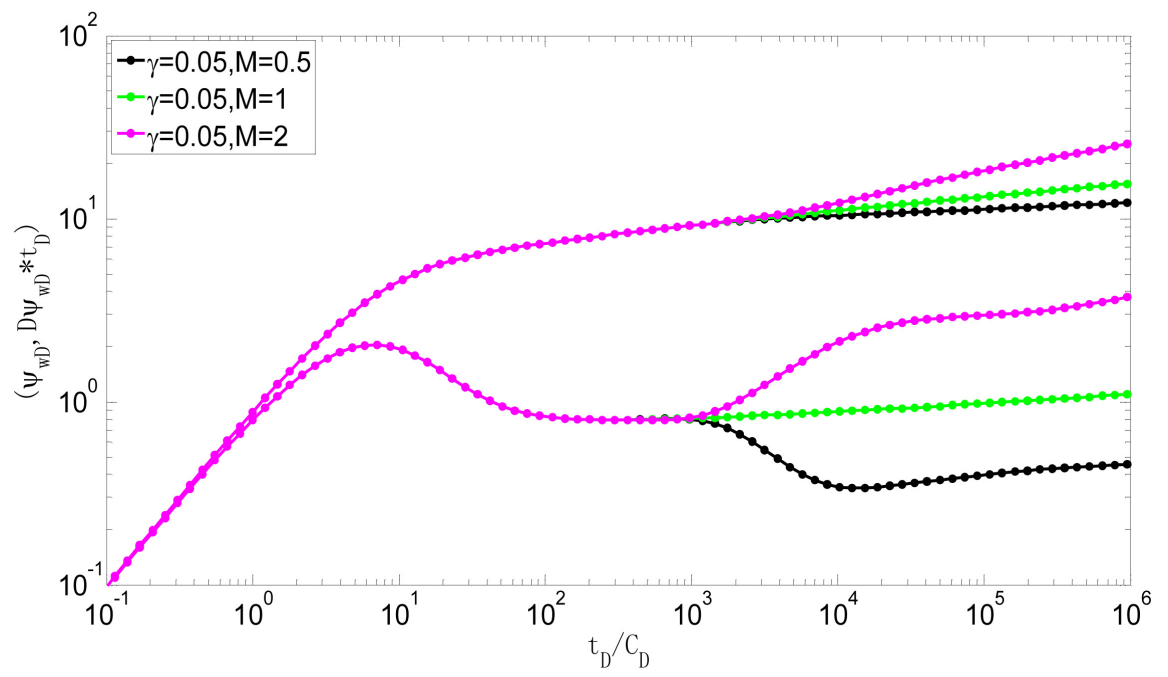

Figure 5. Pressure drop well test curves under different mobility ratios. 
higher the mobility ratio is, the higher the pressure derivative curve and pressure curve of the outer zone radial flow stage are, and the greater the bottom pressure drop is.

\section{Characteristics of Pressure Build-Up Well Test Curve}

The pressure build-up well test curve of composite gas reservoir considering stress sensitivity is shown in Figure 6. It can be seen from Figure 6 that: for pressure build-up test, with the increase of stress sensitivity coefficient, the pressure curve will increase, and the downward migration of pressure derivative curve in inner radial flow stage will become more obvious. With the increase of time in inner radial flow stage, the pressure derivative curve gradually tends to 0.5 horizontal line, while in outer zone radial flow stage, the pressure derivative curve has little difference The results show that with the increase of stress sensitivity coefficient, the faster the formation pressure recovery, the better the formation flow coefficient. The influence of inner radius and mobility ratio on pressure build-up well test curve is consistent with that of conventional composite gas reservoir.

This shows that the permeability damage is caused by stress sensitivity in the production process of gas wells, and the damage range and degree increase with the increase of production time, resulting in the obvious difference between pressure drop curve and pressure recovery curve, which is consistent with the experimental phenomenon. Therefore, for this kind of reservoir, if the conventional reservoir test theory is used to interpret the test data, the pressure drop well test interpretation and the pressure build-up well test interpretation will get the opposite conclusion.

\section{Application and Discussion of the Model}

Well ID-X is the first exploration well successfully tested in the field of ultra-high temperature and ultra-high pressure in Ledong District, Yinggehai

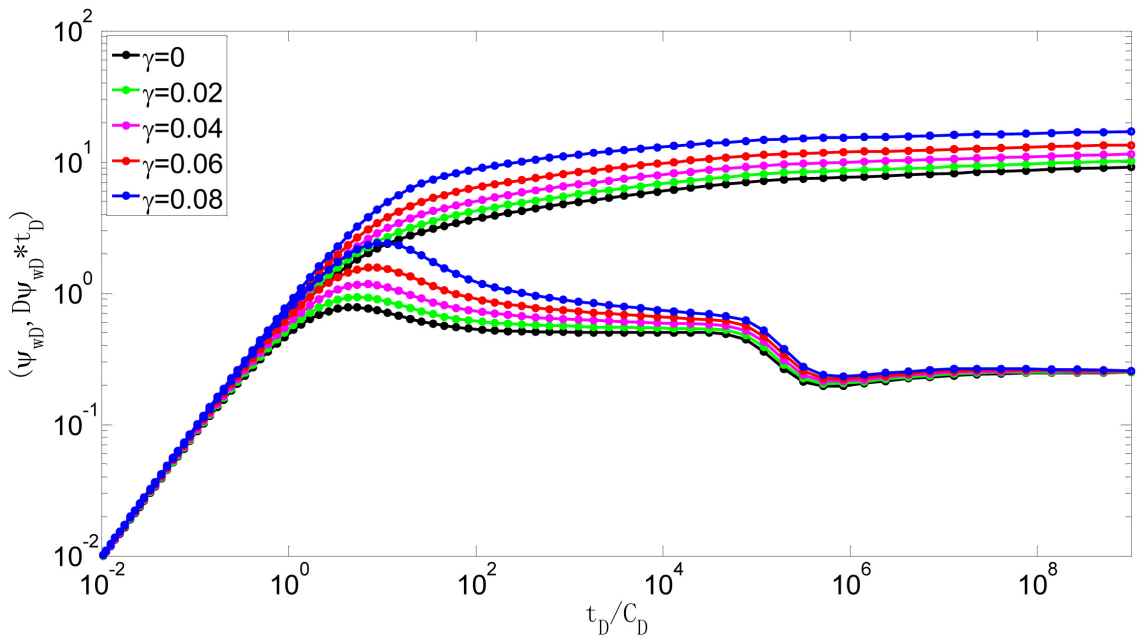

Figure 6. Pressure build up well test curve. 
basin, western South China Sea. The formation pressure coefficient of the well is 2.28. According to previous research results, abnormal high pressure gas reservoirs are generally stress sensitive. In order to fully understand whether the reservoir has stress sensitivity, the productivity test under the condition of step-by-step amplification of differential pressure is designed. The test results of this well are shown in Table 2. The production pressure difference reaches 62.5 $\mathrm{MPa}$ in the production test stage, which is about $70 \%$ of the formation pressure. If there is stress sensitivity, large differential pressure production will cause greater damage to reservoir permeability.

Figure 7 shows the double log curve of pressure build-up test of well LD-X. According to curves of dimensionless pressure and derivative pressure, the flow period was divided into five stages which are wellbore storage, inner transitional flow, inner radial flow, outer transitional flow and outer radial flow. First of all, the pressure wave hasn't propagates to the formation and pressure curve coincided with derivative pressure whose slopes were 1 . Secondly, the dimensionless derivative pressure curve rose and then decreased. And then the pressure wave propagates to the inner region and the gas flowed from inner region to well bottom. Next, the dimensionless derivative pressure curve keeps decreasing. Finally, the pressure wave has arrived in outer area and the gas went from the outer region to the inner.

Table 2. Test results of LD-X well.

\begin{tabular}{cccc}
\hline Choke size & Bottom pressure & Bottom temperature & Daily production \\
\hline$(\mathrm{mm})$ & $(\mathrm{MPa})$ & $\left({ }^{\circ} \mathrm{C}\right)$ & $\mathrm{m}^{3} / \mathrm{d}$ \\
\hline 2.38 & 59.768 & 194.14 & 2.82 \\
3.18 & 49.251 & 194.09 & 4.82 \\
3.97 & 44.353 & 193.49 & 6.98 \\
5.56 & 33.819 & 190.09 & 10.65 \\
7.14 & 26.904 & 185.64 & 12.26 \\
\hline
\end{tabular}

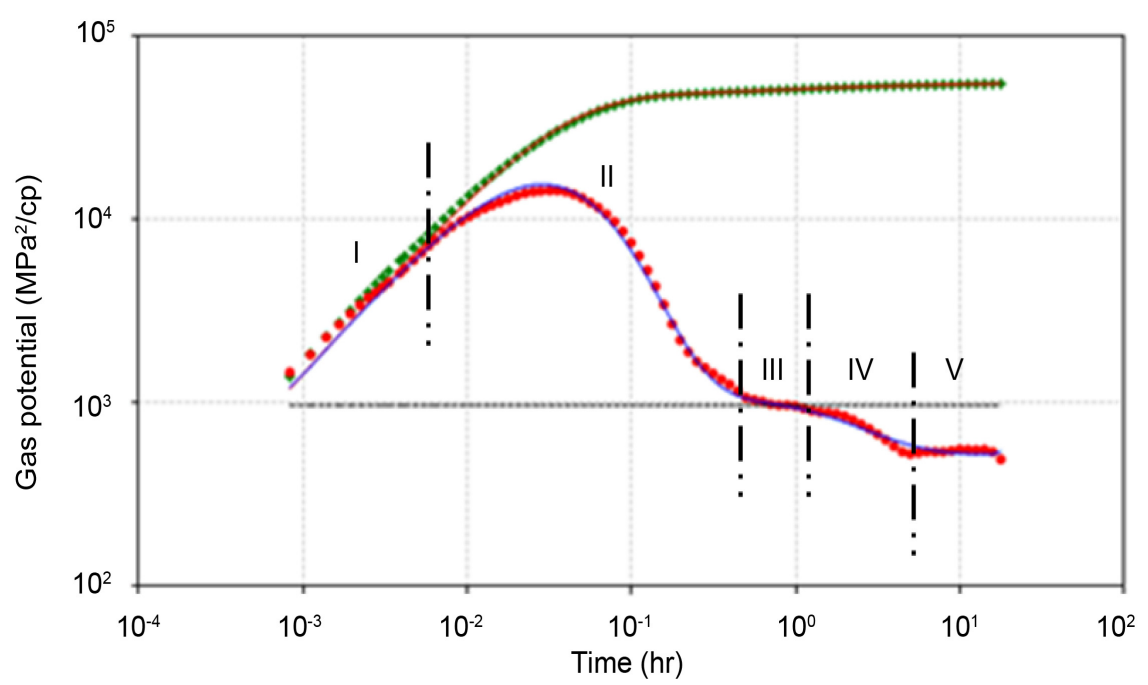

Figure 7. Double log curve of pressure build-up test of well LD-X. 
According to the interpretation of the established well test model, the permeability in the inner zone is $\mathrm{K}=0.73 \mathrm{mD}$, the radius is $20 \mathrm{~m}$, the outer zone is $\mathrm{K}=1.04 \mathrm{mD}$, the skin factor is 20.5 , and the stress sensitivity coefficient is very small, which is 0.0004 , indicating that the reservoir almost has no stress sensitivity.

It is found that: for the abnormal high pressure gas reservoirs with stress sensitive characteristics, the formation rocks generally show the characteristics of under compaction (without discussing the formation with micro fractures), that is, the abnormal formation pressure is caused by unbalanced compaction, such as Kela 2 and the east of Yingqiong basin. According to the pore structure of the formation, the formation pore is composed of "storage pore" and "connected pore", corresponding to "pore" and "throat" in rock. The "storage hole" has high aspect ratio and large volume, which basically represents the size of the total pore. However, the "connected hole" has low aspect ratio and small volume, which controls the flow of fluid in the pore. Compared with the "storage hole", the "connected hole" is more flexible. On the one hand, it is easy to be compressed, on the other hand, it is easy to be opened. Because under compaction delays or prevents normal compaction, the "storage hole" and "connecting hole" are larger than the normal compaction stratum with the same depth, so it is easier to deform and show stress sensitivity. It is found that the formation of overpressure in Ledong area of Yinggehai basin is due to fluid expansion/conduction, and the mechanism of fluid expansion (such as hydrocarbon generation) occurs in deep buried strata. The rapid increase of fluid volume makes the relatively flexible "connecting hole" open, while the rigid "storage hole" is basically unchanged. Therefore, the rigid "storage hole" is basically the same in the process of productivity test and pressure recovery However, only the "connected hole" changes slightly, showing weak or no stress sensitivity. Therefore, not all abnormal high pressure gas reservoirs have stress sensitivity. Except for the influence of micro fractures, the stress sensitivity is related to the formation of abnormal high pressure.

\section{Conclusions}

1) The well test analysis model of heterogeneous composite natural gas reservoir considering the effect of stress sensitivity is established. In the production process, stress sensitivity will cause permeability damage. The pressure drop well test curve shows that the physical properties of the reservoir periphery gradually become worse, and the pressure build-up well test curve shows that the physical properties of the reservoir periphery gradually become better.

2) The field practice of testing reservoir stress sensitivity is carried out. The results show that the stress sensitivity is related to the cause of formation of abnormal high pressure without considering the development of microfractures. The reservoirs with stress sensitivity are generally over pressured due to unbalanced compaction. For the fluid swelling/conductive overpressure reservoirs in 
Ledong District, they are almost not stressed sensitive.

\section{Conflicts of Interest}

The authors declare no conflicts of interest regarding the publication of this paper.

\section{References}

[1] Guo, P., Zhang, J., Du, J.F., et al. (2007) Study on Core Stress Sensitivity for Gas Reservoir with Tow Experiment Method. Journal of Southwest Petroleum University (Science \& Technology Edition), 29, 7-9.

[2] Gao, J., Lu, J. and Wang, J.L. (2009) Evaluation on Stress Sensibility of Low Permeability Rock under Reservoir Condition. Chinese Journal of Rock Mechanics and Engineering, 28, 3899-3902.

[3] Tian, W., Zhu, W.Y., Zhu, H.Y., Zhang, X.-L., et al. (2015) Study on Testing Method of Back-Pressure Stress Sensitivity Evaluation. Natural Gas Geoscience, 26, 377-383.

[4] Xiao, W.L., Li, M., Zhao, J.Z., et al. (2010) Laboratory Study of Stress Sensitivity to Permeability in Tight Sandstone. Rock and Soil Mechanics, 31, 775-779.

[5] Li, C.L. (2006) Evaluation Method for Stress Sensitivity of Reservoir Rock. Petroleum Geology and Oilfield Development in Daqing, 25, 40-42.

[6] Wang, J.J., Liao, X.W., Guo, P., et al. (2014) Stress-Sensitivity Test and Reasonable Proration for Abnormal High Pressure Gas Reservoirs. Natural Gas Exploration and Development, 37, 38-42.

[7] Yang, S.L., Xiao, X.J., Wang, X.Q., et al. (2005) Stress Sensitivity of Rock and Its Influence on Productivity for Gas Reservoir with Abnormal High Pressure. Natural Gas Industry, 25, 94-95.

[8] Tian, L., He, S.L. and Gu, D.H. (2009) Effect of Stress-Sensitivity on Well Test Curve Characteristics in Sandstones Gas Reservoirs. Natural Gas Geoscience, 20, 143-145.

[9] Zhu, L.Y., Yuan, D.W. and Dong, J.X. (2012) Integrated Application of Steady \& Unsteady Well Testing in Radial Composite Gas Reservoir. Well Testing, 21, 11-12.

[10] Tian, L., He, S.L., Gu, D.H., et al. (2006) Study on Well Testing Model and Pressure Characteristics of Heterogeneous Composite Gas Reservoir. Petroleum Geology \& Oilfield Development in Daqing, 25, 61-63.

[11] Li, D.L., Zha, W.S. and Xie, Q. (2013) Influence of Recombination Zone Morphology to Well Test Curve. Well Testing, 22, 31-32.

[12] Fu, W.S., He, S.L., Ran, Y.Z., et al. (2006) Well Test Analytical Model and Pressure Characteristics of Multizone, Non-Isopachous and Lateral Heterogeneous Composite Gas Reservoirs. Oil \& Gas Geology, 27, 124-130.

[13] Zhao, J.Z., Li, J. and Xu, Z.Y. (2017) Advances in the Origin of Overpressures in Sedimentary Basins. Acta Petrolei Sinica, 38, 973-998.

[14] Liu, T. and Liu, J.D. (2018) Quantitative Evaluation on Overpressure Generated from Undercompaction and Fluid Expansion. Acta Petrolei Sinica, 39, 971-979.

[15] Chen, J.H., Luo, Y.T., Liu, K., et al. (2020) A New Method for Gas Well Productivity Analysis Considering Stress Sensitivity. Well Testing, 29, 1-6.

[16] Gao, Y. (2012) Transient Pressure Analysis and Productivity Prediction for Stress Sensitive Shale Gas Reservoir. China University of Petroleum, Shandong. 